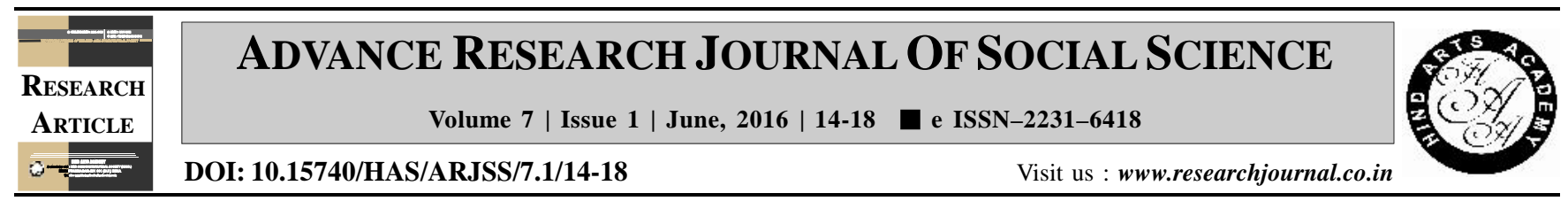

\title{
An analytical study on the development of social skills
}

Anuradha Mahapatra*, Ganga V. Yenagi ${ }^{1}$ and Pushpa B. Khadi

Department of Human Development and Family Studies, College of Rural Home Science, University of Agricultural Sciences, DHARWAD (KARNATAKA) INDIA

${ }^{1}$ Department of Psychology, College of Hanumanmatti, University of Agricultural Sciences, DHARWAD (KARNATAKA) INDIA (Email: anuradhamahapatra2@gmail.com)

\section{ARTICLE INFO :}

$\begin{array}{lll}\text { Received } & : & 23.12 .2015 \\ \text { Revised } & : & 21.03 .2016 \\ \text { Accepted } & : & 03.05 .2016\end{array}$

KEY WORDS :

Social skills, Socio-economic status, Gender

\section{HOW TO CITE THIS ARTICLE :}

Mahapatra, Anuradha, Yenagi, Ganga V. and Khadi, Pushpa B. (2016). An analytical study on the development of social skills.. Adv. Res. J. Soc. Sci., 7 (1) :

14-18, DOI: 10.15740/HAS/ARJSS/7.1/ 14-18.

*Author for correspondence

\begin{abstract}
The study was conducted to know the social skills of high school children. The random sample consisted of 240 high school children (120 boys and 120 girls) studying in class 8, 9 and 10, age ranging from 13 to 15 years drawn from four English medium schools of urban areas in Dharwad city during 2013-2014. Social skills were measured using Social Skills Questionnaire by Spence (1995) and socio-economic status was measured by using socio-economic scale by Aggarwal et al. (2005). Results revealed significant association between age and social skills of high school children, where 14 years children had better social skills compared to 13 years and 15 years children. There was no significant association observed between gender and social skills. However, girls scored more compared to boys. A positive relation was found between socio-economic status and social skills.
\end{abstract}

